\title{
DIFICULDADES DE APRENDIZAGEM NA MATEMÁTICA NAS SÉRIES INICIAIS DO ENSINO FUNDAMENTAL
}

\section{RESUMO}

\author{
Joice Costa de Santana Yazdani ${ }^{1}$
}

A matemática tem sido considerada a disciplina que mais reprova alunos no ensino fundamental, o que chama a atenção de pesquisadores, pois o fracasso nessa disciplina acarretará prejuízo para vida futura do aluno. Baseando-se no princípio de que nenhum conteúdo da aprendizagem escolar é adquirido estaticamente nem pode ser repassado ao aluno como um produto acabado, mas sim deve ser construído através de um processo dinâmico. O estudo parte da premissa de que a despeito de todo avanço na área de ensino, especialmente, da Educação Matemática, ainda assim, existe uma série de práticas conservadoras que ensinam a matéria como se ela fosse algo pronto e acabado, desvinculada da realidade do aluno. Por conta disso, essa análise busca identificar as dificuldades de aprendizagem na matemática, verificando como os jogos podem mediar o processo de ensino e aprendizagem dos conteúdos matemáticos. Para tanto, foi utilizado, enquanto metodologia, a revisão bibliográfica e pesquisa exploratória. $O$ estudo mostra que os resultados da aprendizagem matemática a partir de jogos educativos já são confirmados em vários estudos, pois eles estimulam os alunos a desenvolver o raciocínio lógico, a criatividade e a autonomia intelectual.

PALAVRAS-CHAVE: Matemática. Dificuldade de Aprendizagem. Jogos.

\section{ABSTRACT}

Mathematics has been considered a discipline that most reproaches students in elementary school, which draws the attention of researchers because failure in this discipline will result in injury to the student's future life. Based on the principle that no content of school learning is acquired statically or can be passed on to the student as a finished product, but must be built through a dynamic process. The study assumes that in spite of all advancement in teaching, especially in mathematics education, yet there is a lot of conservative practices that teach the matter as if it were something ready and finished, detached from the reality of student. As a result, this analysis seeks to identify learning difficulties in mathematics, looking at how games can mediate the process of teaching and learning of mathematical content. Thus, it was used as methodology, literature review and exploratory research. The study shows that the results of mathematical learning from educational games are already confirmed in several studies, they encourage students to develop logical reasoning, creativity and intellectual autonomy.

KEYWORDS: Mathematics. Learning Disabilities. Games.

\footnotetext{
${ }^{1}$ Aluna do Mestrado em Ciências da Educação - Facultad Interamericana de Ciências Sociales.
} 


\section{INTRODUÇÃO}

Muitos estudos na área de Educação Matemática, como Alves (2010), D’Ambrósio (2009), Imenes (2008), Machado (2010) e outros, vêm sendo realizados no intuito de compreender as dificuldades na aprendizagem da Matemática. Estes estudos partem do pressuposto de que esta disciplina é efetivamente central na formação dos indivíduos e sua inserção social. Nesse sentido, um insucesso em Matemática significaria um fracasso não apenas na vida escolar, mas na própria condição de cidadão desses indivíduos. Trata-se, portanto, de proporcionar a todos o acesso aos conhecimentos matemáticos.

Mas, apesar dos avanços que estes e outros estudos trouxeram, em muitas escolas, a Matemática ainda vem sendo ensinada como algo pronto e acabado. Por conta disso, os estudos e pesquisa mais recentes em Educação Matemática e as práticas educativas em sala de aula bem-sucedidas sugerem aos professores que busquem desenvolver o processo de ensino e aprendizagem através de atividades lúdicas. Alves (2010), Motta (2014), Kamie e Devries (2008), PCN's (BRASIL/2002), Santos (2010) e outros.

Segundo os Parâmetros Curriculares Nacionais (BRASIL/MEC, 2002), os jogos devem ser valorizados no ensino da Matemática, porque o aluno aprende que precisa ter agilidade, antecipar e coordenar situações, usar estratégias e trabalhar com a memória, usando sua capacidade de concentração e abstração. Assim, as atividades lúdicas no ensino da Matemática têm como objetivo fazer com que o aluno tenha prazer em aprender utilizando técnicas para melhorar a apresentação da disciplina, desenvolvendo o caráter lúdico e a formação de relações sociais.

Introduzindo atividades lúdicas, diminuem-se certos bloqueios que muitos alunos possuem por temerem a Matemática. Os jogos podem possibilitar a compreensão de regras, promovem interesses, satisfação e prazer, formar hábitos e gerar a identificação de regularidades, além disso, facilitam o trabalho com os símbolos e o raciocínio por analogias. Um aspecto relevante nos jogos é o desafio genuíno que eles provocam no aluno, que gera interesse e prazer (ALVES, 2010).

Baseando-se no princípio de que nenhum conteúdo da aprendizagem escolar é adquirido estaticamente nem pode ser repassado ao aluno como um produto acabado, mas sim deve ser construído através de um processo dinâmico, é que se 
objetiva analisar as dificuldades de aprendizagem na Matemática e a importância dos jogos na reversão dessas dificuldades nas séries iniciais do Ensino Fundamental.

Trata-se de uma pesquisa bibliográfica, entendida como atividade básica da ciência na sua indagação e construção com a realidade. Além disso, é a pesquisa que alimenta a atividade de ensino e atualiza frente à realidade do mundo, pois a mesma vincula pensamento e ação.

\section{DIFICULDADES DE APRENDIZAGEM NA MATEMÁTICA}

Muitos estudos na área da Psicologia da Educação vêm sendo realizados no intuito de amenizar a dificuldade na aprendizagem da Matemática. Tais estudos atribuem, historicamente, essa dificuldade a forma como a disciplina tem sido ensinada como algo pronto e acabado. No entanto, pesquisadores enfatizam o quanto à imaginação e a intuição das artes podem ajudar na compreensão dos conteúdos matemáticos.

Segundo Mendes (2012), as dificuldades inerentes à linguagem e ao simbolismo matemático obrigam a tomar o devido cuidado na utilização de tais instrumentos no ensino. A linguagem em si não motiva; as ideias sim. Nenhum aluno pode interessar-se por algo em que não veja algum alimento que satisfaça ou aguce sua curiosidade. Isso é verdade inclusive para os matemáticos que contribuem para o desenvolvimento da sua ciência. Estão interessados nas ideias, métodos e técnicas que fazem parte da sua disciplina. Assim:

Nessa categoria de problemas também entram os padrões, esquemas, palavras-chaves que o estudante deve reconhecer rapidamente para utilizar as técnicas adequadas. As representações geométricas, o reconhecimento de figuras ou de representações gráfica, formam parte das perícias a que fazemos referência neste item. Esses procedimentos incluem doses muito grandes de abstração, pois esses padrões aparecem com apresentações explícitas ou visuais muito diferentes. A interpretação precisa, inclusive visual, de algumas definições abstratas é crucial para avançar na compreensão de diversos entes geométricos: circunferência, paralela, equilátero (GUELLI, 2013, p. 279).

A maior parte das pesquisas sobre os processos de ensino e aprendizagem realizada recentemente tem apontado para o caráter ativo da aprendizagem, considerando, de acordo com Piaget (1997, p. 49) a importância da ação do aprendiz. 
Na concepção piagetiana o ensino da Matemática deve ser beneficiado por um trabalho que incida no desenvolvimento de estruturas do pensamento lógicomatemático. Assim, consideram-se experiências chave para o processo de desenvolvimento do raciocínio lógico e para a aquisição da noção de número as ações de classificar, ordenar/seriar e comparar objetos em função de diferentes critérios.

A importância que o professor atribui a estes aspectos é fundamental para estabelecer a diferença entre um ensino baseado na transmissão ou na construção de conhecimento. O conhecimento se dá na possibilidade de o indivíduo operar sobre o que conhece ou sobre o que memoriza, é justamente nas operações que encontramos a dimensão mais esplêndida do conhecimento, isto é, a possibilidade de gerar novos conhecimentos.

\title{
2.1 Discalculia
}

A matemática para algumas crianças ainda é um bicho de sete cabeças. Muitos não compreendem os problemas que a professora passa no quadro e fica muito tempo tentando entender se é para somar, diminuir ou multiplicar; não sabem nem o que o problema está pedindo. Alguns, em particular, não entendem os sinais, muito menos as expressões. Em muitos casos o problema não está na criança, mas no professor que elabora problemas com enunciados inadequados para a idade cognitiva da criança.

A esse respeito Guelli (2010, p.72) afirma que:

\begin{abstract}
Vários estudos sobre o desenvolvimento da criança mostram que termos quantitativos como "mais", "menos", maior", "menor" etc. são adquiridos gradativamente e, de início, são utilizados apenas no sentido absoluto de "o que tem mais", "o que é maior" e não no sentido relativo de "ter mais que" ou "ser maior que". A compreensão dessas expressões como indicando uma relação ou uma comparação entre duas coisas parece depender da aquisição da capacidade de usar da lógica que é adquirida no estágio das operações concretas"..."O problema passa então a ser algo sem sentido e a solução, ao invés de ser procurada através do uso da lógica, torna-se uma questão de adivinhação.
\end{abstract}

No entanto, em outros casos a dificuldade pode ser realmente da criança e trata-se de um distúrbio e não de preguiça como pensam muitos pais e professores 
desinformados. Em geral, a dificuldade em aprender matemática pode ter várias causas.

De acordo com Sampaio (2009, p.36) existem alguns distúrbios que poderiam interferir nesta aprendizagem:

Distúrbios de memória auditiva: A criança não consegue ouvir os enunciados que thes são passados oralmente, sendo assim, não conseguem guardar os fatos, isto Ihe incapacitaria para resolver os problemas matemáticos.

Problemas de reorganização auditiva: a criança reconhece o número quando ouve, mas tem dificuldade de lembrar-se do número com rapidez.

Estes problemas dificultam a aprendizagem da matemática, mas a discalculia impede a criança de compreender os processos matemáticos. Portanto,

A discalculia é um dos transtornos de aprendizagem que causa a dificuldade na matemática. Este transtorno não é causado por deficiência mental, nem por déficits visuais ou auditivos, nem por má escolarização, por isso é importante não confundir a discalculia com uma simples dificuldade de aprendizagem (SAMPAIO, 2009, p. 23).

O aluno com discalculia comete erros diversos na solução de problemas verbais, nas habilidades de contagem, nas habilidades computacionais, na compreensão dos números. Sampaio (2009) classificou a discalculia em seis subtipos, podendo ocorrer em combinações diferentes e com outros transtornos:

- Discalculia Verbal - dificuldade para nomear as quantidades matemáticas, os números, os termos, os símbolos e as relações.

- Discalculia Practognóstica - dificuldade para enumerar, comparar e manipular objetos reais ou em imagens matematicamente.

- Discalculia Léxica - Dificuldades na leitura de símbolos matemáticos.

- Discalculia Gráfica - Dificuldades na escrita de símbolos matemáticos.

- Discalculia Ideognóstica - Dificuldades em fazer operações mentais e na compreensão de conceitos matemáticos.

- Discalculia Operacional - Dificuldades na execução de operações e cálculos numéricos.

Cabe salientar que, conforme Mendes (2012, p. 34):

[...] independentemente do nível mental, dos métodos pedagógicos usados, e dos distúrbios afetivos, a dificuldade da integração dos símbolos numéricos em sua correspondência com as quantidades reais de objetos é observado em algumas crianças que o valor do número não é relacionado às dificuldades. O menino disléxico transpõe ou inverte letras ou sílabas, 
repete os erros com os números $(6 \times 9) ;(69 \times 96) ;(107 \times 701)$. Isto, porque é lógico, atrasar o numérico e a aritmética que aprendem notavelmente, e provoca uma dificuldade no grafismo dos números ou a interpretação da dificuldade das quantidades nos mecanismos matemáticos e nas operações e de atividades da detecção compreensiva aritmética.

Sampaio (2009) identifica as principais dificuldades do aluno com discalculia: incapacidade de visualizar conjuntos de objetos dentro de um conjunto maior; de conservar a quantidade: não compreendem que 1 quilo é igual a quatro pacotes de 250 gramas; de sequenciar números: o que vem antes do 11 e depois do $15-$ antecessor e sucessor; de classificar números; compreender os sinais,,$+- \div, \times$; de contar operações; de entender os princípios de medida; de lembrar as sequencias dos passos para realizar as operações matemáticas e de estabelecer correspondência um a um: não relaciona o número de alunos de uma sala à quantidade de carteiras.

Os aspectos descritos neste revelam que são várias dificuldades que permeiam a aprendizagem da matemática, o que torna a disciplina que mais reprova nas escolas, sendo assim, faz sentido pesquisar estratégias pedagógicas para o ensino da matemática, buscando entender como se processam a aprendizagem dos conteúdos e aprendizagem nas procura de práticas pedagógicas que visem minimizar as dificuldades dos alunos na assimilação dos conteúdos.

\section{VENCENDO AS DIFICULDADES DE APRENDIZAGEM NA MATEMÁTICA ATRAVÉS DOS JOGOS}

Vários estudos na área de Educação Matemática revelam o quanto à escola moderna ainda tem desenvolvido a tarefa de ensinar essa área do conhecimento de um modo mecânico e estático. Conforme Souza (2009, p. 21), é comum encontrar alunos com dificuldades de aprendizagem na Matemática, pois as aulas são quase sempre ministradas:

[...] de forma mecânica, cansativas, sem estímulo a dúvida; à pesquisa, os conteúdos matemáticos são passados como algo pronto e acabado. Por conta disso, o autor questiona: não será muito mais produtivo incentivar ao aluno a ter ideias matemáticas, dar-lhe oportunidade para expressar, explicar e organizar tais ideias, para finalmente levá-lo a compreender sua aplicação no dia a dia? Nesse último estágio, seria mais conveniente dá ao aluno a oportunidade de verificar tirar suas próprias conclusões, aperfeiçoar sua linguagem e ampliar sem conhecimento sobre o assunto estudado. 
Assim, ao invés de solicitar do aluno a repetição de definições, demonstrações, fórmulas, o professor poderia procurar estratégias para facilitar a aprendizagem de vários conteúdos matemáticos que vêm gerando a não aprendizagem dos mesmos, ocasionando, por sua vez, a reprovação e prejudicando a compreensão de outros conteúdos em séries posteriores (NUNES; CAMPOS, 2008).

Apesar dos avanços nas metodologias de ensino, a Matemática ainda vem sendo ensinada como algo pronto e acabado. Por conta disso, muitos estudiosos enfatizam o quanto as atividades lúdicas podem ajudar na compreensão dos conteúdos matemáticos.

Os estudos de Machado (2009), Almeida (2010) e Alves (2010) fazem uma reflexão sobre o verdadeiro papel do lúdico no Ensino da Matemática. Estes autores fornecem substrato teórico-metodológico, para posicionar como educadores matemáticos frente às tendências atuais, buscando desenvolver estratégias para melhoria do processo de ensino e aprendizagem da Matemática.

Os Parâmetros Curriculares Nacionais (2002), na área de Matemática, estão pautados por princípios decorrentes de estudos, pesquisas, práticas e debates desenvolvidos nos últimos anos. São eles:

- A Matemática é componente importante na construção da cidadania, na medida em que a sociedade se utiliza, cada vez mais, de conhecimentos científicos e recursos tecnológicos, dos quais os cidadãos devem se apropriar.

- A Matemática precisa estar ao alcance de todos e a democratização do seu ensino deve ser meta prioritária do trabalho docente.

- A atividade Matemática escolar não é olhar para coisas prontas e definitivas, mas a construção e a apropriação de um conhecimento pelo aluno, que se servirá dele para compreender e transformar sua realidade.

- No ensino da Matemática, destacam-se dois aspectos básicos: um consiste em relacionar observações do mundo real com representações; outro consiste em relacionar essas representações com princípios e conceitos matemáticos.

- A aprendizagem da Matemática está ligada à compreensão, isto é, à apreensão do significado; aprender o significado de um objeto ou acontecimento pressupõe vê-lo em suas relações com outros objetos e acontecimentos. 
- A seleção e organização de conteúdos não deve ter como critério único a lógica da Matemática.

- O conhecimento matemático deve ser apresentado aos alunos como historicamente construído e em permanente evolução.

- Recursos didáticos como jogos e livros têm um papel importante no processo de ensino e aprendizagem.

Considerando que ensinar Matemática é desenvolver o raciocínio lógico, e para tanto, é necessário estimular o pensamento independente, desenvolver a criatividade, a capacidade de manejar situações reais e resolver diferentes tipos de problemas, com certeza, tem-se que partir em busca de estratégias alternativas.

Os jogos podem ser usados antes da apresentação de um novo conteúdo matemático, para despertar o interesse ou no final para fixar a aprendizagem, desenvolvendo também atitudes e habilidades. É importante que as atividades lúdicas respeitem as características de idade e área de conhecimento.

A utilização de atividades lúdicas em aulas de Matemática desencadeia uma aproximação entre os jogadores, bem como do aluno com o professor. Sabe-se que o jogo é uma atividade desencadeadora de diversas atitudes e não se limita apenas à Matemática nem as crianças da educação infantil e do ensino fundamental. No entanto, essa é uma prática que encontra ainda bastante resistência, quanto da sua aplicação nas aulas, de modo mais específico nas aulas de Matemática, em níveis mais elevados.

A utilização de metodologias lúdicas é restrita a alguns poucos educadores que, não estando satisfeitos com sua prática docente, buscam soluções alternativas. Estas soluções estão hoje pautadas no repensar das questões da aprendizagem significativa, prazerosa e espontânea, uma aprendizagem voltada para o desenvolvimento de valores e atitudes e o preparo do aluno para o desempenho de verdadeira cidadania (O'BRIEN, 2010).

Os jogos oferecem várias formas de aprendizagem. Eles poderão ser idealizados, confeccionados e adaptados se necessário for, de modo a ficar mais claro para o aluno que poderá criar, adaptar, jogar e aprender os conhecimentos matemáticos a partir dos jogos.

Alerta-se, contudo, para a posição a ser tomada pelo professor, em relação à aplicação dos jogos em sala de aula, uma vez que, num primeiro momento, os alunos poderão não se "comportar bem", pois à introdução dessa estratégia, pode 
ser estranho a eles, quebrando a rotina das aulas expositivas. É necessário então, que o professor organize bem essa atividade, estimulando as descobertas e não só as vitórias.

Portanto, o jogo, na educação matemática, passa a ter caráter de material de ensino quando considerado promotor de aprendizagem. Muitos especialistas acreditam que a Matemática deve ser ensinada de forma contextualizada, através de jogos e de análise do cotidiano dos alunos.

Todavia, para que a inserção dos jogos ocorra, de preferência ainda na fase escolar inicial, necessário se faz uma política de conscientização e capacitação do professor, enquanto agente modificador, para que o mesmo possa aperfeiçoar o ensino tradicional através da inclusão de atividades lúdicas, quebrando os paradigmas existentes para uma melhor formação do aluno.

Vale ressaltar que, apesar dos jogos deverem ser introduzidos ainda na fase escolar inicial, os mesmos podem ser inseridos em qualquer fase da vida de uma pessoa, promovendo, inclusive, abertura para modificações comportamentais, visto que durante os jogos as pessoas revelam facetas de seu caráter que normalmente não exibem por recear sanções.

Portanto, assim como são inúmeros os benefícios, também são inúmeras as variedades de jogos que o educador pode utilizar em sala de aula. Entretanto, devese atentar para escolher adequadamente um jogo, de modo que o mesmo facilite o processo de aprendizagem de seus alunos e que desperte a ludicidade, visto que é "a mão humana que lhe dá direção é que define a ética e o seu uso" (MOTTA, 2014, p. 38).

Sendo assim, as atividades lúdicas, respeitadas às características de idade e área de conhecimento, contribuem para a aprendizagem de Matemática no ensino fundamental a partir da dinâmica que imprime às relações professor-alunoconhecimento e do seu caráter concreto.

A utilização de atividades lúdicas em aulas de Matemática, além dos aspectos cognitivos relevantes para a sua aplicação, não deve ignorar ou menosprezar o aspecto afetivo, desencadeado pela ação do jogo, na aproximação dos jogadores, bem como do aluno com o professor. Essa ocorrência é verificada em Piaget (1997) como em toda conduta humana o aspecto cognitivo é inseparável do aspecto afetivo, compreendido como a energia da ação que permeia a motivação, o interesse e o desejo. 
Kishimoto (2010, p. 20), enfatiza que: "cresce o número de autores que adotam o jogo na escola assumindo o significado usual: incorporando a função lúdica e a educativa". Assim, os jogos se apresentam como possibilidades alternativas que conduzem à compreensão de estruturas matemáticas consideradas de difícil entendimento. Todavia, todas e quaisquer atividades lúdicas a ser praticada em sala de aula deve ser previamente planejada e o professor deve estar atento às seguintes questões:

$\checkmark$ A finalidade especifica da atividade;

$\checkmark$ Se a atividade vai exigir material permanente ou improvisado;

$\checkmark$ Se envolverá competitividade;

$\checkmark$ O tempo necessário para a execução da atividade;

$\checkmark$ Como será apresentada a atividade;

$\checkmark$ A designação que será dada.

Entretanto, após a aplicação da atividade lúdica o professor deve fazer uma avaliação crítica para analisar se as finalidades foram alcançadas, assinalando os pontos que podem ser melhorados ou retirados.

Além disso, é comprovado por experiências práticas, que o ensino direto de conceitos é infrutífero. Deve-se sim, gerar oportunidades para que o sujeito adquira novos conceitos, palavras, conhecimentos, num contexto de relações internas e externas, entre as coisas, uma com as outras, já que o conhecimento é adquirido pela criação de relações e não por exposição de fatos e conceitos isolados.

Ademais, considera-se ser educativo trabalhar com jogos, pois ajudando a lidar com a competição gerada nos jogos. Assim, pelas atividades lúdicas praticadas em grupos, oportunizam-se a formação de alunos seguros, que possam ganhar jogos sem ser agressivo, como perdê-los sem se traumatizarem.

Acrescenta-se que os alunos só adquirirão uma postura crítica em relação aos conhecimentos matemáticos através de um trabalho competente do professor, que os levem a ser capazes de interpretar, analisar e comparar as informações matemáticas que vivenciam no dia-a-dia, avaliando sua consistência e veracidade.

Para o ensino de Matemática, que se apresenta como uma das áreas mais caóticas em termos da compreensão dos conceitos nela envolvidos, pelos alunos, o elemento jogo se apresenta com formas específicas e características próprias, 
propícias a da compreensão para muitas das estruturas matemáticas existentes e de difícil assimilação.

De forma resumida pode-se afirmar, conforme Passos (2011), que o trabalho com jogos matemáticos em sala de aula nos traz vários benefícios, isto é, para professores e principalmente para os alunos:

a) detectar os alunos que estão com dificuldades reais;

b) o aluno demonstra para os colegas e professores se o assunto, desenvolvido em outras atividades, foi bem assimilado ou não;

c) a competição saudável existente nas atividades de jogos, entre jogadores e adversários, faz com que eles almejem vencer e por isso aperfeiçoam-se e ultrapassam limites;

d) os jogos são capazes, através da elaboração de caminhos para a resolução da situação problema gerada, de levar o aluno a formular e reformular conceitos;

e) durante o desenrolar dos jogos, pode-se observar que os alunos tornam mais críticos, alerta e confiantes, elaborando perguntas e tirando conclusões sem necessidade da interferência ou aprovação do professor;

f) o aluno se empolga com o clima de uma aula diferente, o que faz com que aprenda sem perceber.

Portanto, a escola precisa oferecer situações de problematizações, levando o aluno a refletir sobre a realidade, aprendendo a utilizar as diversas possibilidades que os recursos pedagógicos oferecem. Nesse sentido, a função do professor tornase extremamente importante, ou seja, mediar o processo ensino e aprendizagem no contexto educativo, o que requer novas formas de atuação que levem em conta a inserção e disseminação dos recursos lúdicos na sociedade e na Educação Matemática.

\section{CONSIDERAÇÕES FINAIS}

Como visto na revisão de literatura, inúmeros são os fatores que interferem na aprendizagem. A atividade lúdica é intrínseca ao próprio ser humano, independente da sua classe social, faixa etária ou sexo. O jogo didático é um elemento propulsor 
no processo de aprendizagem e é também a forma mais eficiente de despertar a motivação. Infelizmente, esta prática ainda não ganhou a confiança de muitos professores, especialmente, dos que trabalham com o ensino da matemática.

O ensino dos conteúdos matemáticos deve buscar a aplicabilidade da Matemática no dia a dia do aluno, como também mostrar para o ele a importância que desta ciência no desenvolvimento da humanidade. Para tanto se faz necessário pesquisa, questionamento e busca constante do saber matemático. Seguindo esse princípio, o aluno-cidadão é preparado para não para a reprodução do conhecimento, mas sim para julgar e agir diante das adaptações impostas pelas mutações da vida social e profissional.

Acredita-se que a missão da escola no século XXI é desenvolver potencialidades e formar cidadãos. Seu principal papel é ajudar o aluno a superar suas dificuldades a partir de mudanças nas atividades de ensino. Por isso, o professor precisa mudar sua metodologia, desenvolver estratégias inovadoras, a fim de que seu aluno aprenda a Matemática de forma prática. É nesse contexto que os jogos ganham importância, uma vez que no ambiente escolar trazem muitas vantagens para o processo de ensino e aprendizagem.

Como guisa de conclusão, ressalta-se que os jogos no ensino da Matemática possibilitam um esforço espontâneo e voluntário do aluno para atingir o objetivo, mobilizando esquemas mentais, estimulando o pensamento, a ordenação de tempo e espaço.

\section{REFERÊNCIAS}

ALMEIDA, Paulo Nunes de. Educação lúdica e jogos pedagógicos. São Paulo: Loyola, 2010.

ALVES, Eva Maria Siqueira. A ludicidade e o ensino de matemática: uma prática possível. Campinas: Papirus, 2010.

BRASIL, Ministério da Educação e do Desporto. Secretaria de Educação Fundamental. Parâmetros Curriculares Nacionais. PCN'S. Brasília: MEC/SEF, 2002.

D'AMBROSIO, U. Da realidade à ação: reflexões sobre educação e matemática. Campinas: Papirus, 2009. 
GUELLI, Ricardo. Matemática da mão para cabeça. Revista Nova Escola. V. 10. № 89. nov., 2010.

IMENES, C. A Matemática em sala de Aula. In Revista do Professor, Ano 3, $\mathrm{n} \cong 12$, 2008.

KAMIE, Constance; DEVRIES, L. A criança e o número. Campinas: Papirus, 2008.

KISHIMATO, T. Morchida. O Jogo e na educação. São Paulo: Pioneira, 2010.

MACHADO, F. Criatividade e processos de criação. Petrópolis: Vozes, 2010.

MENDES, Paulo O. O desenvolvimento psicológico da criança. Rio de Janeiro, Zahar, 2012.

MOTTA, Júlia. Jogos: repetição ou criação? São Paulo: Plexus, 2014.

NUNES, M. C; CAMPOS, T. Matemática ideias e desafios. São Paulo: Saraiva, 2008.

O'BRIEN, Thomas. Abaixo a matemática do papagaio. In: Revista Nova Escola. № 134. Agosto, 2010.

PASSOS, L. C. O uso da história da matemática na formalização de conceitos. São Paulo: Artes Médicas, 2011.

PIAGET, J. - Para onde vai a educação? Rio de Janeiro: Ed. José Olympio, 1997.

SAMPAIO, César. Aprendizagem escolar e construção de conhecimento através dos jogos. Porto Alegre: Artes Médicas, 2009.

SOUZA, Deleusa Machado de Freitas. 0 ensino da matemática através de jogos aplicado nas séries iniciais. Formosa-go, dezembro, 2009. 